\title{
ATTITUDE OF CONSUMERS AND ISSUE OF CREDIBILITY IN FACEBOOK ADVERTISING OF COUNTERFEIT PRODUCTS
}

\section{Muhammad Umer Alvi ${ }^{1}$}

\begin{abstract}
One of the reasons affecting the perception of consumers and their attitude towards buying the product is the credibility of Facebook Advertisement and the Counterfeit Product. In this modern age where the consumers are well aware about the products. They research thoroughly about the product before proceeding towards the last stage of the buying cycle. Social Media Platforms have made our lives easier. Everything we want to know is on our fingertips. However, research studies on SNS's and how they are perceived by its users are relatively limited especially how online factors influence users' perceptions and attitudes towards advertising of Counterfeit products on SNS's. This paper aims to examine the online factors that influence consumers' perceptions and attitudes towards advertising of counterfeit products on Facebook. Total 30 respondents participated in our research paper. The results suggest that there are five online factors that significantly influence consumers' attitudes towards advertising on Facebook. The factors are Credibility, Entertainment, Perceived Interactivity, Privacy and Ad Avoidance. The result of this study revealed that the independent variables have a significant effect and positive influence on dependent variable. All hypotheses were accepted. The study helps in understanding the consumer attitude towards the Facebook advertisement of counterfeit products.
\end{abstract}

Keywords: Attitudes towards Advertising, Social Networking Sites (SNS), Facebook, Advertising Credibility, Counterfeit Products.

\section{INTRODUCTION}

Over the years, advertising has drastically evolved. In the ever-changing world, marketers find creative ways to stay ahead of the curve. Marketers always seek for innovative and interactive way to connect with the in order to advertise and promote their products efficiently. The

\footnotetext{
${ }^{1}$ Institute of Business Management, Karachi, Pakistan
} 
objective is to get maximum views and interactions on the content through latest creative piece of art. Nowadays, brands are bringing differentiation by adapting unique ways of advertising their communication.

Advertising avoidance, credibility, privacy, perceived interactivity, privacy, and entertainment play a vital role in consumer's attitude towards the product because these factors act as a barrier or increase efficiency in delivering effective messages to the target audience and in return, it helps in spreading the brand awareness among audience.

The social media platforms are cleverly used such as Facebook, Twitter, Instagram, and YouTube in order to promote the brand's identity and spread the whole communication among the audience. Marketers analyze their advertisement through trial and error whereby some of their creative artworks are recognized on international level through which they continue to follow the same footstep. Online Advertisement has greatly boomed over the years because it is the best way to reach out to the millions of users who are always on their phones, laptops, tablets and digital watches. It is very important to effectively tap on the touch points and plan the media buying else, there is a possibility that the ads are shown to people who are not the target audience. This could wrongly exhaust all the media budget while showing it to the irrelevant audience. The type of content plays a vital role on consumer's perception. User search for the original product that can be beneficial for them but if unfortunately they face the bad experience on buying the counterfeit products, this can result in trust issues in their buying pattern. There are multiple sellers online who tries to grab audiences' attention via advertising counterfeit products by claiming them original, but users are well informed about the forums and online reviews add further information that can protect them from a bad shopping experience. While there are some users who comes under the false advertisement but this result in being vigilant in buying behavior for the next time. Therefore, the objective of this research paper is to study the consumer perception and their attitude towards advertisement of the counterfeit products and the factors that affect their mindset and behavior. Marketers are increasingly building effective communication with audience through digital media among the audience platforms and they are approaching new techniques to convert the potential customers and maintaining trust and brand image among the audience. Facebook has grown drastically over the period of time and it has become a primary platform for the audience. People increasingly consume the Facebook content and advertisement as it has become a mandatory part of their daily routine (Akar \& Topcu, 2011; Kim \& Ko, 2012). Actually, the social media platforms has become an effective marketing tools for the marketers and brand managers to 
spread awareness, build engagement, increase sales, generate traffic for their specific campaigns and create value by emphasizing on the blue ocean strategy (Kim \& Ko, 2010).

Actually, this robust social media platform has created an exemplary scope for any brand to advertise its product through exposure, attention, and perception; to develop opinions; and to create values (Kim \& Ko, 2010). Several researchers have studied the impact of viral and influential marketing among audience and how it grab audiences' attention that develops their attitude towards the product and overall brand. How effective it is and in what manner it turns the user into potential customers (Cho, 2004).

So far, celebrities and bloggers/influencers has played a vital role in building the brand perception and changing the consumer attitude towards the product however there are many influencers who are being used to change the consumer perception about the counterfeit products through positive word of mouth. This is also evident considering different trust disposition models credibility and reputation development concepts (Shareef et al., 2019), and human psychological theories (Ajzen, 1991). Shareef et al. (2019) summarized the questions to better understand the consumer attitude and their perception of advertisement of counterfeit products on Facebook.

1. How the bloggers/influencers and opinion leaders are effective in building the brand perception among audience and changing their attitude towards the product through impactful advertisement.

2. Are there any differences in terms of credibility for the advertisement of the product among different sects of audiences and generating the positive word of mouth regarding the fake products who should be held responsible for changing the mindset of audience?

The current study has enormous theoretical and practical value in terms of the scope of viral marketing on Facebook and how it is considered for future promotional technique.

\section{Statement of the Problem}

The problem of counterfeit products being advertised on social media platforms especially Facebook, where millions of people are spending time. The attitude of consumers is a crucial issue for research. It has negative impact on the consumer's attitude to buy counterfeit products as the problem statement is:

"The attitude of consumers and issue of credibility in Facebook advertising of counterfeit products" 


\section{Research Questions}

- $\quad$ Are customers effected by the advertisements of counterfeit products?

- Does counterfeit product advertisements effects customer's attitude?

- Does counterfeit product advertisements poses threat of credibility in Facebook?

\section{Objectives of the Study}

To study aims to evaluate impact on consumer's attitude and issue of credibility in Facebook advertising of counterfeit products.

- $\quad$ To review the past literature on the constructs taken for the study.

- To empirically test the role of counterfeit advertisements on Facebook, and impact on consumer's attitude.

- To empirically test the influences of demographics on customer online purchase intention of counterfeit products among audience

This paper aims to examine the relationship between five factors of consumers attitude towards advertisements of counterfeit products on Facebook. In particular, this study will examine the relationship between perceived interactivity, advertising avoidance, credibility, entertainment and privacy

\section{LITERATURE REVIEW}

It is evident, that a lot of research is being carried out on attitude and behavior of customers towards advertisements. Digital advertisements are now taking over conventional methods as people spend most of their time on social media. Some research suggests people spend approximately two hours and twenty-two minutes in a single day on social networking websites (digitalinformationworld.com). During this time people are exposed to hundreds of advertisements and people make their purchase decisions. During this time people are exposed to hundreds of advertisements and people make their purchase decisions (Penz \& Stottinger, 2005). The counterfeit products that seem identical to the original product is increasingly produced and distributed among the audience at a high rate all over the globe. The counterfeit products are produced using a very simple technology, yet marketers changed the brand perception by creating value to it and advertising it through positive word of mouth and USP.

However, counterfeiting looms in two forms, the deceptive and non-deceptive counterfeiting. In the first stage, consumer is not aware of the fact that it is the replica of the original product and it is fake product that is being marketed in a wrongful manner through communicating it 
in a way that its original. A pervious study by (Debatin, Lovejoy, Horn, \& Hughes, 2009) studied that the online advertisement through social media platforms are fully dependent on the way consumer perceive the advertisement and the way the value is being created as it is being communicated to different SECS that comes under the target audience of the campaign. Unlike the research published in 2013 (Yaakop et al., 2013) found perceived interactivity as an imperative influence in consumer responses to the same subject. Perceived Interactivity is the degree of opportunities for customer engagement with media content. In order to analyze the consumer perception towards the online advertisement, the dimensions such as privacy, credibility and advertising avoidance were previously used to identify the consumer attitude (Kelly et al., 2010). Another variable is taken entertainment which is an important tool to measure consumer's engagement with the advertisements, whether consumers are entertained while going through the advertisements that are available for viewing.

Therefore, in analogy with the past studies, research proposes that consumer's attitude and issue of credibility in Facebook advertising of counterfeit products. It portrays a generalized perception of customer's behavior while looking at advertising of counterfeit products (Nordin, 2009).

By definition, the Digital Media can be thought of in various ways. From a functional perspective, it is an assortment of technological-based innovations-normally introduced with different platforms such as Facebook, Instagram, Twitter, YouTube and mobile applications and websites - that gives brands an edge to advertise themselves through different ways to put across their communication among the target audience. In other words, we can say that digital media platforms are a bridge to interact with the audience through advertising. In any case, we can likewise consider digital media more comprehensively, considering it to be as computerized media and explicit innovation, and more as advanced spots where individuals connect with their belongings (Appel et al., 2010)

Various brands build their visibility and personality through digital media platforms. They build strong association with the target audience by capitalizing on different trends and occasional events. Also, the brand develop their personality by celebrating the occasional event that is relatable with their brands. The overall tone and communication of the brand explains the brand personality and hence it helps in interacting with the meaningful audience (Cho, 2004). 
Facebook is the primary medium for the online advertisement. It involves huge number of audience therefore it has given the opportunity to various brands to advertise itself through different ways such as Brand Video integration on different channels that can help the brand visibility among the audience to spread awareness about the product. Facebook has also empowered the brands to manage the ads by targeting audience through their interests, behavior, demographics, geographical location, and age group and gender so that ads can be viewed to those who are the relevant audience (Whitelock, Cadogan, Okazaki, \& Taylor, 2013).

Advertisement plays a major role in consumer attitude. The perception of the consumer is built upon what they see. What they see is what they believe, similarly ads smartly translate the brand communication in consumer's mind however successful advertisement wins consumers' heart only if it resonates with the target audience.

According to the consumer insight, the emotional ads touch the heart string of the consumer. The successful ads are always memorable, relatable and scalable. It is not mandatory to push your product forcefully in the advertisement. The ads in which insight and concept is strong and the product is shown in a subtle manner are more frequently watched than the ones in which the product is forcefully visible. Thousands of sellers are available on Facebook to sell their products and services however some of them sell the counterfeit products to audience in order to earn maximum profit as much as they can. The seller of counterfeit products portrait themselves as the original brand by communicating and representing themselves in such a way that the user perceive them as the original brand. Taking into account that consumers are increasingly consuming online content when using social media platforms, it is important to understand the factors that affect the consumer attitude towards the Facebook advertisements of counterfeit products and to study the extent that it's affected via influential marketing or becoming a fan of a page or a brand (Nordin, 2009).

Restricted research has been conducted in endeavoring to address the variables that drive consumers' perspectives toward SNS advertisement and how it can influence their expectations to take an interest in eWOM practices and their aims to buy products and services from various brands. The sellers of counterfeit products lose their consumers gradually for trading in a wrongful manner therefore some of the consumers spread the negative word of mouth among their friends and family and on different Facebook communities so that other user doesn't fall under the same radar. Due to this reason, there's an issue of credibility for the advertisement of counterfeit products (Nordin, 2009). 


\section{CONCEPTUAL FRAMEWORK}

The literature considers attitude as a dependent variable and perceived interactivity, advertising avoidance, credibility, entertainment, and privacy as independent variables. These constructs have been used in previous studies which have proposed models depict that perceived interactivity, advertising avoidance, credibility, entertainment and privacy significantly predicts attitude towards advertisements on Facebook (Yaakop et al., 2013). On the basis of these facts, the conceptual framework of this study is developed using the variables as demonstrated in Figure-1.

Figure 1: Conceptual Framework

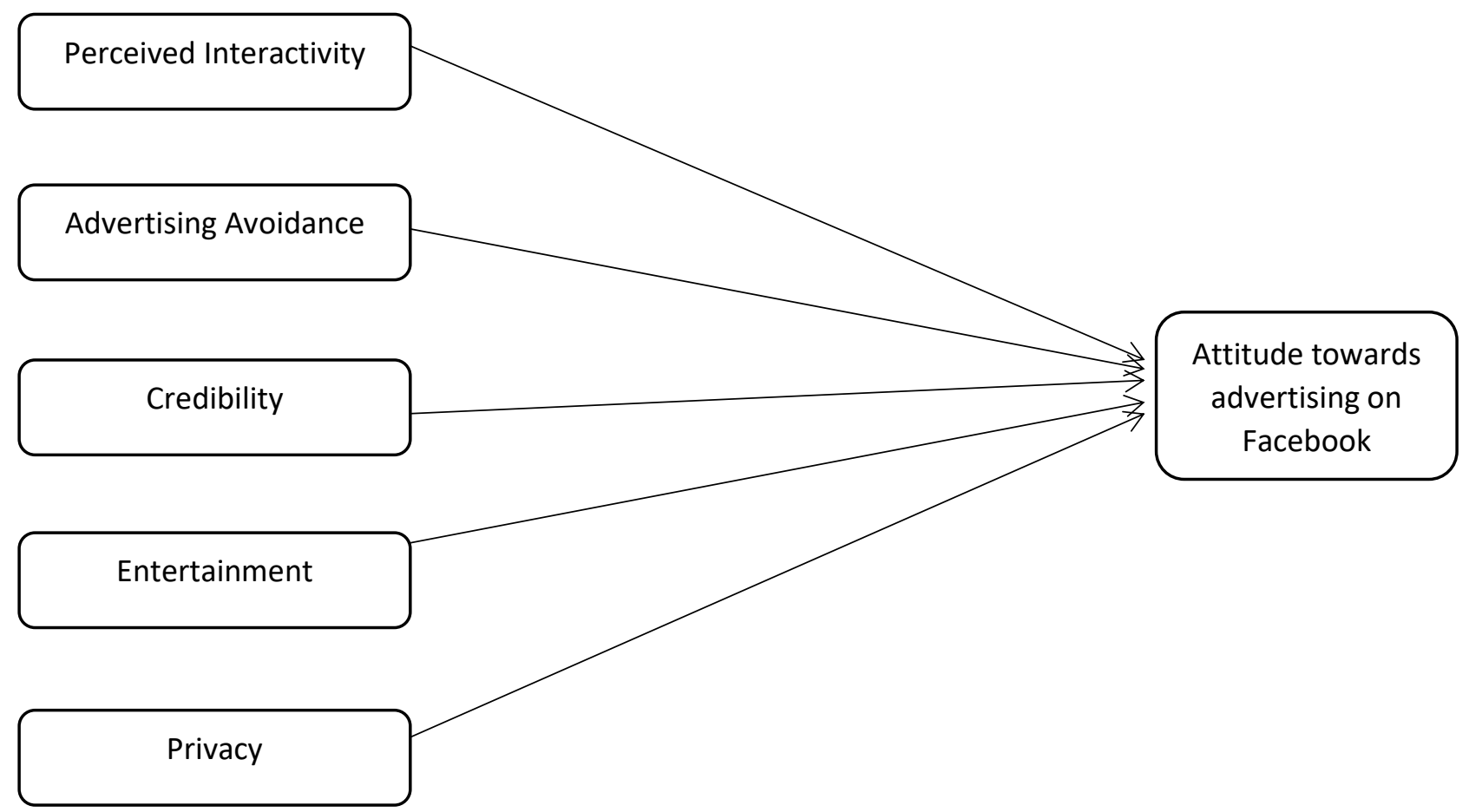

\section{Perceived Interactivity}

Interactivity is an important objective to gauge the campaign performance of the brand. The interaction is checked through the user engagement on Social Media Sites. The number of engagement includes likes + comments + shares. User participation towards the brand campaign is high if it tends to resonate with them. Its highly important to build association with the audience in order to build strong connection with them.

One of the interactive ways to grab audiences' attention is through innovative creative ads such as Facebook Environment ads, Carousel Ads, Canvas Ads, 3D virtual display, animated ads, 
images, etc. The strategy is to interact with the audience and direct them towards the campaign objective. (Khang et al., 2012)

It is pertinent to mention that if there is an increase in stages of interactivity by the audience then they have a positive and favorable perception /attitude towards the Facebook advertisement on the digital media platforms and the engagement rate of the audience to interact on the content is high because they liked the content hence likes/shares and comments increases. Consumers can shop online on Facebook as well through different communities where seller directly interact with the users and share all the relevant details.

Also, Facebook has enabled online shopping whereby users are directly on the website and place their order. Facebook has also enabled the marketers to manage their ads through which they can target their audience as per the interest, demographics, behavior, age groups, gender, geographical location, etc. so the ad is only viewed to those who are the relevant audience. (Shareef et al., 2019)

Moreover, marketers can also manage their ads by reviewing how the campaign is performing. It also provides the numbers of the target audience and statistics of how many people interacted on the content posted. Facebook also analyze the interested users who search on Google regarding the things that our product can solve their problems hence Facebook automatically target them, and the content is reached to those audience.

To emphasize on the definition, it means to picture the online experience of the consumers. The marketer can gauge the performance by analyzing their interaction and engagement online. We can define the interactivity as following

The degree to which the user interacts with the brand and takes interest in the product and services, attentive towards the communication and messages received, and being influenced by the advertisement shown (Shrum, 2002).

\section{Hypothesis 1: There is a significant effect of Perceived Interactivity on attitude.}

\section{Advertising Avoidance}

It is examined that how the Facebook Ad Manager benefits the campaign performance when audience has the privilege to avoid the advertisement whenever they want to though marketer can narrow down the targeting based on their campaign objective so that it is shown to the people who are interested buyers, but user has all the right to avoid the advertisement whenever 
they want to. They analyzed that the blocking of an ad may discourage the content and investment of the media budget put into the campaign (Johnson, 2013)

When people dislike the advertisement, they might switch to other content because they find the advertisement quite confusing, monotonous, and irritating or any attribute that results in dis-likeness of the content. (Speck \& Elliot, 1997). Negative beliefs means that when the seller is advertising the products that are deceptive and misleading in order to force people to buy the products hence it results in promoting or advertising undesirable values. (Pollay \& Mittal, 1993; Shavitt et al., 1998). However positive attitude of the consumers towards the advertisement results in decrease in ad avoidance (Rojas-Mendez \& Davies, 2005), and may include the notions that advertising can be informative and reduce future search time. People who avoid television advertising can have quite different motives for doing so they may avoid commercials. (a) In search of relief from boredom and boring commercials. (b) Due to the excess of television commercials. (c) As a result of their curiosity to see what current scenarios is and (d) because of their affinity with television. In which case the very process of zapping may be gratifying and serve as an enjoyable activity for the viewer. A useful way to summarize attitudes towards advertising is that such attitudes will be overall positive or negative, underpinned by the competing beliefs that advertising is inherently useful or that it promotes unwanted consumption (Rojas-Méndez \& Davies, 2005).

\section{Hypothesis 2: There is significant effect of advertising avoidance on attitude.}

\section{Credibility}

Credibility refers to the extent the audience believes in conventional and online marketing tools. The Marketing Tools such as TVC, Radio Advertisement, Print Media, Brand Activations and Online Advertisement such as the brand advertisement on various digital media platforms such as Facebook, Instagram, Twitter, YouTube, Website, Google Ads, Mobile Application, etc. Millions of audience access through countless advertisement on daily basis. As per the Consumer Insight, the younger people view Online Advertisement while the older age groups consumer traditional advertisement to consume the information as credibility. Consumers trust the information given by verified pages on Facebook and therefore are more willing to purchase the products and services however the unauthorized pages on Facebook have least credibility as there is a factor of misleading information given on such pages without any assurance. As per the consumer insight, the younger generation and people who work tends to consume more online shopping than older generation and house wives because it's more convenient for them to shop online rather than going to the physical outlets. However as time is passing by, people are getting more aware about the online shopping and credibility of 
the advertisement on Facebook. They tends to shop from the pages that are verified and endorsed through positive word of mouth by bloggers and influencers (Vinerean et al., 2013).

\section{Hypothesis 3: There is significant effect of credibility avoidance on attitude.}

\section{Privacy}

The privacy issue has always been the main concern of the public. The personal information of the user is easily accessible to anyone on Facebook such as name, age, interest, behavior, activities, buying pattern, address, contact details, pictures, documents, etc. However, the brands provide the $100 \%$ assurance to the audience that private information would be kept confidential and would not be misused at any point. People provide their personal information to brands online while making a purchasing decision and tends to do online shopping without any hassle and misuse of the personal information. Individuals even provide their data to the e-commerce sites (Fortes \& Rita, 2016).

\section{Hypothesis 4: There is a significant effect of privacy on attitude.}

\section{Entertainment}

In the modern era, audience tends to consume online and traditional advertisement that entertain them in any perspective either it is through emotional, humorous, social, fear, romantic, celebrity endorsement, youth, musical, adventurous, empathy or testimonial appeal. It is observed that people love to be entertained and similarly they would love to view the advertisement again and again if they are entertained while consuming it. Advertisement should have the power to grab audiences' attention. Nowadays, brands are playing with consumer psyche through creative and innovative ad which can be powerful yet thumb stopping. New trends are coming up as day pass by and marketers are experimenting to work with the best use of artificial intelligence and creativity to come up with the out of the box ideas (Cunningham \& Craig, 2017).

Apart from advertisement, influencers and celebrities are playing a vital role in keeping the audience entertained through different activities. They translates the brands communication in a way that audience grasp the main message and get awareness of the product and at the same point, they gives them a positive feedback regarding the product.

The other ways to interact with the target audience on Facebook is through live sessions whereby you can connect with the user and solve their queries instantly. You can talk to them in real time and educate them regarding the product through virtual display. 
Digital Industry is growing drastically, and marketers are well-aware of the fact. They are capturing their TG through online mediums as people spend most of their daily routine while surfing internet. Audience consume online content to entertain themselves and digital is the best option to indulge in loads of entertainment stuff.

Researchers conduct the extensive research therefore several researchers (Debatin, Lovejoy, Horn, \& Hughes, 2009; Di Pietro, Di Virgilio, \& Pantano, 2012; Shareef et al., 2019) found that the consumers build perception when they view an advertisement however thousands of ads are shown to the consumers on social media networks and users build different perception when they view a communication regarding the product or service (Hayes \& King, 2014). . Some of the users are sharp enough to interpret the product and services through the reviews generated by people who have experienced the product and some of them are persuaded via communicated message being advertised to them (Akar \& Topcu, 2011; Kim \& Ko, 2012; Pietro \& Pantano, 2012; Shareef et al., 2019). Some of the user use the social media networks for the entertainment purpose and share it with their peer and social circle to put the message across and being indulged in entertainment activity (Hayes \& King, 2014; Pelling \& White, 2009).

\section{Hypothesis 5: There is a significant effect of Entertainment on Advertising avoidance.}

\section{METHODOLOGY}

In order to conduct the research on consumer attitude towards advertisement, the authors surveyed advertisers, marketing students and brand managers as sample population because they exemplify a major market segment. The authors kept them as the main focus for our research because they have excellence in marketing and advertisement so they can better understand the consumer attitude and their mindset towards Facebook Advertisement regarding counterfeit products which will help us get the proper research of our topic. Young Generation such as students are majorly consuming online advertisement and digital media content. We used them as sample group because they know the latest digital media trends and current affairs, innovation, creative takeovers on Digital Media Platforms so it is best to use them to get the proper research. The total number of samples selected is 200 however the instrument is developed in English. The data collection was examined through SPSS 17.0 and Sample PLS model. The instrument contains 32 items about perception towards Facebook Advertisement and the Consumer Attitude towards advertisement on Facebook 


\section{DATA ANALYSIS}

\section{Factor Analysis}

Thirty-two (32) items questionnaire was used to analyze the Consumer Perception towards advertisement of Facebook and Consumer Attitude towards the advertising of counterfeit products on social network.

\section{Instrumental Development}

The questionnaire was created on the basis of six constructs, Attitude consisted of four items, Advertising Avoidance consisted of four items, Perceived Interactivity consisted of four items, Credibility has three items, Entertainment has four items and in the last Privacy consisted of four items. The questionnaire was adopted from previous research (Yaakop et al., 2013). Similar study was conducted i.e. Attitude of Consumers and Issue of Credibility in Facebook Advertising, however slight amendment was made by incorporating counterfeit products.

\section{Scale and Measures}

The research tends to focus on key area i.e., advertisement of counterfeit products. In total (38) items were there in the questionnaire including demographics, while 24 items were representing the constructs. The scale used to obtain responses is a 5-point Likert Scale in which (1) stands for Strongly Agree and (5) stands for Strongly Disagree. The reliability for the questionnaire adopted for the research was tested and Cronbach's Alpha is greater than 0.7 which shows the instrument was satisfactory. The questionnaire was divided into 6 parts i.e., Demographics, Attitude, Perceived Interactivity, Advertising Avoidance, Credibility, Entertainment and Privacy.

\section{Data Collection}

This study involved gathering primary data in order to understand the perspective of consumers with respect to advertisements of counterfeit products. In the process of collecting primary data, this research conducted online survey so that the targeted sample can be reached easily. The advantage of collecting primary data is that it provides relevant information required to test the established hypothesis from the real world perspective. The collection of primary data helped in understanding the perspective and attitude of customers and credibility of Facebook advertising.

\section{Data Analysis}


The data collection in the study is analyzed using quantitative data analysis technique. Some statistical tests are performed on SPSS in order to generate results and to determine whether the hypothesis are rejected or failed to reject. The tests that are conducted to evaluate the constructs and its items are descriptive statistics, correlation analysis, reliability analysis.

\section{RESULTS}

\section{Demographic Analysis}

The research is conducted on sample size of 203 individuals in which 53.2\% were females and $46.7 \%$ were males. Similarly approximately $40 \%$ of the respondents represented age group of (23-28). Furthermore, $30.5 \%$ of the respondents represented age group of (18-22). $17.7 \%$ of the respondents belonged to the age group of (29-32) and 9.8\% belonged to the age group of (32 \& above). In terms of income level $29 \%$ of the respondents had income level from (25000 to 35000 ). Further $27 \%$ of the respondents had income level of ( $71000 \&$ above). Remaining $20.1 \%$ of the respondents had income level of (36000 to 50000) and $18.7 \%$ had income level of (51000 to 70000). In the end our research topic is focused on Facebook, so we asked our respondents regarding number of years they have been using Facebook in which 36.9\% respondents have been using it from 7 to 9 years. $34.9 \%$ respondents have been using for more than 10 years. Similarly, 20.6\% have been using Facebook from 4 to 6 years. 5.9\% of the respondents are using Facebook from 1-3 years.

\section{Descriptive Statistics}

The regression analysis cannot be conducted on the data if it does not follow normal distribution. In order to ensure the normality conditions followed in the collected data, the descriptive analysis is tested. If the ranges of skewness and kurtosis are between -2 and +2 , the data is considered as normal Table-1 illustrates the overall descriptive statistical analysis, which includes the sample mean, standard deviation, skewness, and kurtosis.

Table 1: Descriptive Statistics and Reliability Analysis

$\begin{array}{lllll}\text { Mean } & \text { Std. Dev. Skewness } & \text { Kurtosis } & \begin{array}{l}\text { Cronbach's } \\ \text { Alpha }\end{array} & \begin{array}{l}\text { Composite } \\ \text { Reliability }\end{array}\end{array}$




\begin{tabular}{|c|c|c|c|c|c|c|}
\hline tttitude & 2.45 & 0.64 & -0.41 & 0.06 & 0.69 & 0.81 \\
\hline Perceived & 2.26 & 0.67 & 0.25 & 0.14 & 0.69 & 0.80 \\
\hline \multicolumn{7}{|l|}{ Interactivity } \\
\hline Advertising & 2.32 & 0.79 & 0.23 & -0.62 & 0.74 & 0.83 \\
\hline \multicolumn{7}{|l|}{ Avoidance } \\
\hline Credibility & 2.17 & 0.69 & 0.50 & 0.70 & 0.70 & 0.83 \\
\hline Privacy & 2.48 & 0.68 & -0.30 & -0.23 & 0.63 & 0.78 \\
\hline Entertainment & 2.56 & 0.49 & 0.45 & -0.31 & 0.62 & 0.78 \\
\hline
\end{tabular}

\section{Reliability of the Constructs}

The internal consistency and closely related items in a normally distributed data are checked by the Cronbach's alpha value which confirms the data is reliable, if the value of Cronbach alpha is greater than this means the data is reliable. However as can be seen in Table-1 the value of Cronbach's alpha is greater than 0.6, and composite reliability, which is also known as construct reliability much like Cronbach's alpha (Netemeyer, 2003). Composite reliability values of 0.60 to 0.70 are acceptable in exploratory research, while in more advanced stages of research, values between 0.70 and 0.90 can be regarded as satisfactory (Alwitt \& Prabhaker, 1994). Whereas the instrument used in this study was taken from a previously conducted research, however some amendments were made and due to which the test was conducted again. Therefore, the reliability test by using Cronbach's alpha was conducted for the purpose of study, and the summary of results is depicted in Table-1.

Table- 1 shows that the reliability of attitude towards advertising avoidance and credibility is highest $(\alpha=0.83, \mathrm{M}=2.32, \mathrm{SD}=0.79)$ and $(\alpha=0.83, \mathrm{M}=2.17, \mathrm{SD}=0.69)$. However, the relationship of dependent variable (i.e., attitude) with independent variables (i.e., Perceived interactivity, Privacy and Entertainment) is similar with composite reliability values ranging from 0.78 to 0.80 . The overall reliability composite reliability value of the instrument is 0.83 which includes both the independent and dependent variables.

\section{Correlation Analysis}

Correlation may be described as the degree of association between two variables (Asuero, Sayago, \& Gonz'alez, 2016). The test of correlation analysis assures the multi-collinearity among variables in order to conduct to regression analysis. Fundamentally, the coefficient of correlation $\mathrm{R}$ will range between -1 and +1 . According to Gogtay and Thatte (2017), by measure, the correlation coefficient can be interpreted based on its value. Scholars suggest that correlation amongst the constructs should lie between 0.2 and 0.9 otherwise item should be 
discarded. If the correlation coefficient is greater than 0.90 , the items can be merged together (Dobele et al., 2007). The correlation analysis is depicted in Table-2.

Table 2: Correlation Results

\begin{tabular}{lllllll}
\hline & AdAvoid & Attitude & $\mathrm{Cr}$ & Ent & PI & PR \\
\hline Advertising & 1.00 & & & & & \\
Avoidance & & & & & & \\
Attitude & 0.33 & 1.00 & & & & \\
Credibility & 0.52 & 0.43 & 1.00 & & & \\
Entertainment & 0.49 & 0.29 & 0.57 & 1.00 & & \\
Perceived & 0.57 & 0.36 & 0.52 & 0.52 & 1.00 & \\
Interactivity & & & & & & \\
Privacy & 0.21 & 0.58 & 0.28 & 0.27 & 0.29 & 1.00 \\
\hline
\end{tabular}

\section{Construct Validity}

When constructs are adopted in any research, their validity must be ensured due to variance which might occur because of cultural and demographical differences (Ahmed et al., 2019). The constructs used in this study were previously used in studies as well, so concentrating them according to Pakistani environment may affect the results. Therefore, to maintain uniformity in the study it was required to assure the validity of the respondent's data. Construct validity is determined by conducting the tests of "convergent validity" and "discriminant validity" (Fornell \& Larcker, 1981). The test of construct validity can be determined by looking at AVE the values should be greater than 0.40. Since all the values of Average Variance Explained is greater than 0.40 , this means that the data fulfills the requirements of the convergent validity (Hair Jr et al. 2017).

\section{Discriminant Validity}

Discriminant validity interprets that two measures that are not supposed to be related are in fact, unrelated. The term "discriminant validity" stems from theoretical approaches in validity that focus on the construct (e.g., Cronbach \& Meehl, 1955). The discriminant validity is conducted by comparing the amount of the variance capture by the construct and the shared variance with the constructs (Fornell \& Larcker, 1981). Thus, the level of square root of the AVE for each construct should be greater than the correlation involving the constructs. It is noticed that the square root of variance explained is greater than the correlation of all the 
constructs, this primarily indicates that the constructs used in this study are distinct and unique. The results are summarized in Table- 3 .

Table 3: Discriminant Validity

\begin{tabular}{lllllll}
\hline & AdAvoid & Attitude & Cr & Ent & PI & PR \\
\hline Advertising & 0.75 & & & & & \\
Avoidance & & & & & & \\
Attitude & 0.33 & 0.72 & & & & \\
Credibility & 0.52 & 0.43 & 0.79 & & & \\
Entertainment & 0.49 & 0.29 & 0.57 & 0.69 & & \\
Perceived Interactivity & 0.57 & 0.36 & 0.52 & 0.52 & 0.71 & \\
& & & & & & \\
Privacy & 0.21 & 0.58 & 0.28 & 0.27 & 0.29 & 0.69 \\
\hline
\end{tabular}

\section{Regression}

For the purpose of testing the hypothesis, regression analysis has been conducted to determine the impact of each independent variable (perceived interactivity) on dependent variable (attitude of consumers).

Security Risk. To test the hypothesis "Perceived Interactivity positively influences consumers' attitude"

\begin{tabular}{cccccc}
\hline & \multicolumn{5}{c}{ Standardized } \\
Variable & $\mathrm{B}$ & Std. Error & Beta & T & Sig. \\
\cline { 2 - 4 } (Constant) & 2.94 & 0.08 & & 13.415 & .000 \\
PI & 0.20 & 0.07 & -0.22 & 0.19 & 0.000 \\
\hline
\end{tabular}

a. Dependent Variable: Att.

Advertising Avoidance: The simple regress is conducted to test the hypothesis "Advertising avoidance significantly impact consumers' attitude".

Regression Result (AA)

\begin{tabular}{cccccc}
\hline & \multicolumn{5}{c}{ Standardized } \\
Variable & Un standardized Coefficients & Coefficients & & \\
\cline { 2 - 4 } (Constant) & 3.36 & Std. Error & Beta & T & Sig. \\
AA & 0.25 & 0.07 & -0.23 & 15.724 & .000 \\
& & & & & \\
\hline
\end{tabular}

a. Dependent Variable: Att

Credibility: The simple regression analysis is conducted to test the hypothesis "Credibility significantly effects consumers' attitude”. 
Regression Result (CR)

\begin{tabular}{llrrrrrr}
\hline & & \multicolumn{2}{c}{$\begin{array}{c}\text { Un standardized } \\
\text { Coefficients }\end{array}$} & \multicolumn{2}{c}{$\begin{array}{c}\text { Standardized } \\
\text { Coefficients }\end{array}$} & & \\
\cline { 3 - 5 } Model & & B & \multicolumn{2}{c}{ Std. Error } & Beta & \multicolumn{1}{c}{ T } & \multicolumn{1}{c}{ Sig. } \\
\hline 1 & (Constant) & 2.04 & 0.07 & & 9.619 & .000 \\
& CR & 0.17 & 0.08 & 0.24 & 2.496 & .000 \\
\hline
\end{tabular}

a. Dependent Variable: Att

Entertainment: The simple regression analysis is conducted to test the hypothesis

"Entertainment significantly effects consumers' attitude."

Regression Result (Ent)

\begin{tabular}{|c|c|c|c|c|c|c|}
\hline \multirow{2}{*}{\multicolumn{2}{|c|}{ Model }} & \multicolumn{2}{|c|}{$\begin{array}{l}\text { Un standardized } \\
\text { Coefficients }\end{array}$} & \multirow{2}{*}{$\begin{array}{l}\text { Standardized } \\
\text { Coefficients } \\
\text { Beta }\end{array}$} & \multirow[b]{2}{*}{$\mathrm{T}$} & \multirow[b]{2}{*}{ Sig. } \\
\hline & & $\mathrm{B}$ & Std. Error & & & \\
\hline & (Constant) & 3.35 & 0.07 & & 9.619 & .000 \\
\hline & ENT & 0.25 & 0.08 & 0.18 & 2.496 & .004 \\
\hline
\end{tabular}

Dependent Variable: Att

Privacy. The simple regression analysis is conducted to test the hypothesis "Privacy significantly effects consumers' attitude."

Regression Result (PR)

\begin{tabular}{|c|c|c|c|c|c|c|}
\hline \multirow{2}{*}{\multicolumn{2}{|c|}{ Model }} & \multicolumn{2}{|c|}{$\begin{array}{l}\text { Un standardized } \\
\text { Coefficients }\end{array}$} & \multirow{2}{*}{$\begin{array}{c}\text { Standardized } \\
\text { Coefficients }\end{array}$} & \multirow[b]{2}{*}{$\mathrm{T}$} & \multirow[b]{2}{*}{ Sig. } \\
\hline & & B & Std. Error & & & \\
\hline \multirow[t]{2}{*}{1} & (Constant) & 6.44 & 0.07 & & 9.619 & .000 \\
\hline & PR & 0.43 & 0.06 & 0.43 & 2.496 & .000 \\
\hline
\end{tabular}

a. Dependent Variable: Att

\section{DISCUSSION \& CONCLUSION}

A questionnaire was distributed among the students at Institute of Business Management and Brand Managers \& Advertisers of various organizations. The demographic characteristics of the responded are listed in the table 1 that is presented below. Scale ablution process is very important for assessing the reliability and validity of measured scales. This process involves evidence of theoretical content as well as validated empirical tests in order to evaluate the quality of the data. The item analysis is conducted to ensure non-violation of normality assumptions, reliable and valid prior to multivariate analysis. With the help of this study, we have explained the significance of perceived interactivity, advertising avoidance, credibility, entertainment and privacy have effect on attitude of customers. The consumer's attitude towards advertisements of counterfeit products make difficulties for people to make their 
purchase decisions. This in turn also raises question on the authenticity of Facebook dealing with such fake content in order to regain confidence and trust of customers. It also signifies brands to take pro-active measures to report such fake contents to the Facebook administration. The result of this study was found reliable with previous studies. Further explanation of the hypothesis, the stated findings of this study are discussed in detail below

\section{RESEARCH LIMITATIONS AND SCOPE FOR FUTURE RESEARCH}

The current study focused on evaluating the impact of 5 factors of consumer attitude towards the Facebook Advertisement on counterfeit products. The future studies can enhance their scope by conducting the research on different continents of the world so that we can get the findings in broad perspective. Currently, the research was conducted in Pakistan. In order to study the Consumer Attitude towards the Facebook advertisement of counterfeit products and the issue of credibility, the research can be taken from different countries to study that how people of different countries behave towards counterfeit products and their attitude towards all the other 5 factors of attitude towards Facebook advertisement.

Moreover, Digital Media plays a vital role for future research - in light of distinguished requirements for new information - proposes that this sub-field will turn out to be substantial after some time. We urge researchers in marketing to examine the consumers on social media. As we examined before in our study that online networking is a fascinating and innovative took of marketing, however it is the manner by which individuals utilize internet based life and the technology that transmit the communication in users' mind in a very interactive and creative manner. In looking into the internet-based life biological system and thinking about where it is going with regards to consumers and advertisement, there is a future scope for advertisement and unlimited innovation that is coming along on the way. The eventual fate of internet based life in promoting and energizing, yet in addition dubious. In the case of nothing else, it is essentially important that we better comprehend online networking since it has gotten exceptionally socially applicable, a prevailing type of correspondence and articulation, an important media type utilized by organizations for promoting and different types of correspondence, and even has geopolitical implications. We trust that the thoughts talked about here invigorate numerous new thoughts and research, which we at last plan to see being referenced and shared over each kind of online life stage. 


\section{REFERENCES}

Ahmed, S., Ansari, J., Khan, Y. W., \& Ramish, M. S. (Spring 2019). Are Bank Employees Satisfied with Perceived Leadership and Empowerment? The Lahore Journal of Business $7(2), 95-120$

Ajzen, I. (1991). The theory of planned behavior. Organizational behavior and human decision processes, 50(2), 179-211.

Akar, E., \& Topçu, B. (2011). An examination of the factors influencing consumers' attitudes toward social media marketing. Journal of internet commerce, 10(1), 35-67.

Alwitt, L. F., \& Prabhaker, P. R. (1994). Identifying who dislikes television advertising: Not by demographics alone. Journal of Advertising Research, 34(6), 17-30.

Appel, G., Grewal, L., Hadi, R., \& Stephen, A. T. (2010). The future of social media in marketing. Journal of the Academy of Marketing Science,48(1), 79-95, https://doi.org/10.1007/s11747-019-00695-1

Cho, C. H. (2004). Why do people avoid advertising on the internet? Journal of advertising, 33(4), 89-97.

Cronbach, L. J., \& Meehl, P. E. (1955). Construct validity in psychological tests. Psychological bulletin, 52(4), 281.

Cunningham, S., \& Craig, D. (2017). Being 'really real'on YouTube: authenticity, community and brand culture in social media entertainment. Media International Australia, 164(1), 71-81.

Debatin, B., Lovejoy, J. P., Horn, A. K., \& Hughes, B. N. (2009). Facebook and online privacy: Attitudes, behaviors, and unintended consequences. Journal of computer-mediated communication, 15(1), 83-108.

Di Pietro, L., Di Virgilio, F., \& Pantano, E. (2012). Social network for the choice of tourist destination: attitude and behavioural intention. Journal of Hospitality and Tourism Technology.

Dobele, A., Lindgreen, A., Beverland, M., Vanhamme, J., \& Van Wijk, R. (2007). Why pass on viral messages? Because they connect emotionally. Business Horizons, 50(4), 291304. 
Fornell, C., \& Larcker, D. F. (1981). Structural equation models with unobservable variables and measurement error: Algebra and statistics.

Fortes, N., \& Rita, P. (2016). Privacy concerns and online purchasing behaviour: Towards an integrated model. European Research on Management and Business Economics, 22(3), 167-176.

Gogtay, N. J., \& Thatte, U. M. (2017). Principles of correlation analysis. Journal of the Association of Physicians of India, 65(3), 78-81.

González, A. G., Herrador, M. Á., Asuero, A. G., \& Sayago, A. (2006). The correlation coefficient attacks again. Accreditation and Quality Assurance, 11(5), 256-258.

Hair Jr, J. F., Matthews, L. M., Matthews, R. L., \& Sarstedt, M. (2017). PLS-SEM or CB-SEM: updated guidelines on which method to use. International Journal of Multivariate Data Analysis, 1(2), 107-123.

Hayes, J. L., \& King, K. W. (2014). The social exchange of viral ads: Referral and coreferral of ads among college students. Journal of Interactive Advertising, 14(2), 98-109.

Johnson, J. P. (2013). Targeted advertising and advertising avoidance. The RAND Journal of Economics, 44(1), 128-144.

Kelly, L., Kerr, G., \& Drennan, J. (2010). Avoidance of advertising in social networking sites: The teenage perspective. Journal of interactive advertising, 10(2), 16-27.

Khang, H., Ki, E. J., \& Ye, L. (2012). Social media research in advertising, communication, marketing, and public relations, 1997-2010. Journalism \& Mass Communication Quarterly, 89(2), 279-298.

Kim, A. J., \& Ko, E. (2010). Impacts of luxury fashion brand's social media marketing on customer relationship and purchase intention. Journal of Global Fashion Marketing, 1(3), 164-171.

Kim, A. J., \& Ko, E. (2012). Do social media marketing activities enhance customer equity? An empirical study of luxury fashion brand. Journal of Business research, 65(10), 14801486.

Netemeyer, R. G., Bearden, W. O., \& Sharma, S. (2003). Scaling procedures: Issues and applications. Sage Publications. 
Nordin, N. (2009). A study on consumers' attitude towards counterfeit products in Malaysia (Doctoral dissertation, University Malaya).

Pelling, E. L., \& White, K. M. (2009). The theory of planned behavior applied to young people's use of social networking web sites. CyberPsychology \& Behavior, 12(6), 755759.

Penz, E., \& Stottinger, B. (2005). Forget the Areal@ thingbtake the copy! An explanatory model for the volitional purchase of counterfeit products. ACR North American Advances.

Pollay, R. W., \& Mittal, B. (1993). Here is the beef: factors, determinants, and segments in consumer criticism of advertising. Journal of marketing, 57(3), 99-114.

Rojas-Mendez, J. I., \& Davies, G. (2005). Avoiding television advertising: Some explanations from time allocation theory. Journal of Advertising Research, 45(1), 34-48.

Shareef, M. A., Mukerji, B., Dwivedi, Y. K., Rana, N. P., \& Islam, R. (2019). Social media marketing: Comparative effect of advertisement sources. Journal of Retailing and Consumer Services, 46, 58-69.

Shavitt, S., Lowrey, P., \& Haefner, J. (1998). Public attitudes toward advertising: More favorable than you might think. Journal of advertising research, 38(4), 7-22.

Shrum, L. J. (2002). Media consumption and perceptions of social reality: Effects and underlying processes. Media effects: Advances in theory and research, 2, 69-95.

Speck, P. S., \& Elliott, M. T. (1997). Predictors of advertising avoidance in print and broadcast media. Journal of Advertising, 26(3), 61-76.

Vinerean, S., Cetina, I., Dumitrescu, L., \& Tichindelean, M. (2013). The effects of social media marketing on online consumer behavior. International Journal of Business and Management, 8(14), 66.

Whitelock, J., Cadogan, J. W., Okazaki, S., \& Taylor, C. R. (2013). Social media and international advertising: theoretical challenges and future directions. International marketing review.

Yaakop, A., Anuar, M. M., \& Omar, K. (2013). Like it or not: Issue of credibility in Facebook advertising. Asian Social Science, 9(3), 154. 